\title{
Prognostic Role of Hypoxia-Inducible Factor-2 $\alpha$ Tumor Cell Expression in Cancer Patients: A Meta-Analysis
}

\section{OPEN ACCESS}

Edited by:

Massimo Bonora,

Albert Einstein College of Medicine,

United States

Reviewed by:

Anca Maria Cimpean,

University of Medicine and

Pharmacy, Timisoara, Romania

Adriana De Siervi,

Instituto de Biología y Medicina Experimental (IBYME), Argentina

Julie Valerie Decock,

Qatar Biomedical Research

Institute, Qatar

*Correspondence:

Marc Vooijs

marc.vooijs@maastrichtuniversity.nl

Specialty section:

This article was submitted to Molecular and Cellular Oncology,

a section of the journal

Frontiers in Oncology

Received: 20 March 2018

Accepted: 30 May 2018

Published: 11 June 2018

Citation:

Moreno Roig E, Yaromina A, Houben $R$, Groot AJ, Dubois $L$ and Vooijs M (2018) Prognostic Role of Hypoxia-Inducible Factor-2 $\alpha$ Tumor Cell Expression in Cancer Patients: A Meta-Analysis.

Front. Oncol. 8:224.

doi: 10.3389/fonc.2018.00224

\author{
Eloy Moreno Roig1, Ala Yaromina1, Ruud Houben², Arjan J. Groot', Ludwig Dubois ${ }^{1}$ and \\ Marc Vooijs ${ }^{1 *}$
}

' Department of Radiotherapy (MAASTRO)/GROW - School for Developmental Biology and Oncology, Maastricht University, Maastricht, Netherlands, ${ }^{2}$ Department of Radiation Oncology, MAASTRO Clinic, Maastricht, Netherlands

Hypoxia-inducible factor-2 $\alpha$ (HIF-2 $\alpha$ ) plays an important role in tumor progression and metastasis. A number of studies have evaluated the correlation between HIF-2 $\alpha$ overexpression and clinical outcome in cancer patients but yielded inconsistent results. To comprehensively and quantitatively summarize the evidence on the capability of HIF-2 $\alpha$ to predict the prognosis of cancer patients with solid tumors, a meta-analysis was carried out. Renal cell carcinoma (CC-RCC) was separately analyzed due to an alternative mechanism of regulation. Systematic literature searches were performed in PubMed and Embase databases for relevant original articles until February 2018. Fortynine studies with 6,052 patients were included in this study. The pooled hazard ratios (HRs) with corresponding confidence intervals were calculated to assess the prognostic value of HIF-2 $\alpha$ protein expression in tumor cells. The meta-analysis revealed strong significant negative associations between HIF-2 $\alpha$ expression and five endpoints: overall survival [HR $=1.69,95 \%$ confidence interval (95\% Cl) 1.39-2.06], disease-free survival $(H R=1.87,95 \% \mathrm{Cl} 1.2-2.92)$, disease-specific survival $(H R=1.57,95 \% \mathrm{Cl} 1.06-2.34)$, metastasis-free survival $(H R=2.67,95 \% \mathrm{Cl} 1.32-5.38)$, and progression-free survival $(H R=2.18,95 \% \mathrm{Cl} 1.25-3.78)$. Subgroup analyses revealed similar associations in the majority of tumor sites. Overall, these data demonstrate a negative prognostic role of HIF-2 $\alpha$ in patients suffering from different types of solid tumors.

Keywords: cancer, hypoxia-inducible factor-2, meta-analysis, prognosis, endothelial PAS domain protein-1

\section{INTRODUCTION}

Hypoxia is a common feature of most of solid tumors resulting from an imbalance between oxygen supply and consumption by tumor cells. Hypoxic tumor areas are characterized by a disrupted vasculature causing inefficient oxygen and nutrient supply to neighboring cells (1). Hypoxia is one of the key factors in inducing the development of resistant cells with an aggressive phenotype (2), which leads to poor prognosis in patients and decreases the efficacy of chemoradiotherapy $(3,4)$. Accurate measurement of tumor hypoxia in patients together with the design of novel anti-hypoxia treatments has largely been a major goal in cancer research (5-8).

Hypoxia triggers important cellular stress responses allowing tumor cells to survive under extreme conditions, including the stabilization of the hypoxia-inducible factor (HIF) proteins $(9,10)$. Under normoxic conditions, prolyl-hydroxylation promotes HIF- $\alpha$ degradation via the von Hippel-Lindau (VHL) ubiquitin/proteasome pathway. Under hypoxia, this regulation is 
suppressed, leading to the stabilization of three independent HIF- $\alpha$ subunits (HIF- $1 \alpha$, HIF- $2 \alpha$, and HIF- $3 \alpha$ ) that dimerize with the constitutively expressed HIF-1 $\beta$ and activate the transcription of genes via hypoxia responsive elements in their promoter region. The HIF-2 $\alpha$ protein, also named endothelial PAS domain protein-1, is equally oxygen regulated as its counterpart HIF- $1 \alpha$, and both present over $50 \%$ similarity in their amino acid sequence identity (11). In physiologic conditions, HIF- $1 \alpha$ has a broad activity in several tissues which contain hypoxic regions, while HIF- $2 \alpha$ is more restricted to specific cell types, e.g., kidney, lung, and heart (12). HIF proteins distinctly contribute to the upregulation of genes involved in proliferation, glucose metabolism, and angiogenesis and genes involved in invasion and metastasis in different types of cancer (13). HIF isoforms also differ in their ability to promote treatment resistance in cancer by playing highly divergent or even opposite roles, leading to distinct clinicopathologic features and prognosis (14). Specific activity of HIF- $2 \alpha$ differently contributes to total HIF target gene expression among many types of cancers, which may influence the characteristics of these tumors and the outcome of patients (15). To date, much effort has been made to better understand the roles of HIF- $2 \alpha$ in cancer and the consequences for patients suffering from high-HIF- $2 \alpha$ expressing tumors. So far, there is clear evidence suggesting that HIF- $2 \alpha$ is a crucial protein for the development and progression of many types of cancer. Indeed, HIF- $2 \alpha$ seems to be crucial in regulating multiple aspects in cancer, including cell proliferation, apoptosis, epithelial-to-mesenchymal transition, cell metabolism, angiogenesis, and resistance to therapy $(16,17)$. Hypoxia-induced HIF-2 $\alpha$ expression and its subsequent chain of events make this protein a relevant marker of tumor hypoxia and a promising target for anticancer therapies with novel inhibitors.

Several clinical studies describe the prognostic value of HIF$1 \alpha$ in cancer, including the elaboration of many meta-analyses for several kinds of cancer and different HIF- $1 \alpha$ polymorphisms (18-20). For some of the clinical studies included in these meta-analyses, prognostic data on HIF- $2 \alpha$ can be found which often differed from HIF- $1 \alpha$ data (21). In addition, other studies specifically looked at the role of HIF- $2 \alpha$ independently of HIF$1 \alpha$ expression. Nonetheless, many discrepancies are seen among the investigations that were performed during the last years, in which HIF- $2 \alpha$ has been reported to be either a positive or negative prognostic factor in cancer. The purpose of this meta-analysis was to provide an updated comprehensive analysis regarding the prognostic value of HIF- $2 \alpha$ expression in solid tumors.

\section{MATERIALS AND METHODS}

\section{Literature Search}

The research question of this meta-analysis was defined as follows: "what is the prognostic value of tumoral HIF- $2 \alpha$ expression in patients with solid tumors?" Meta-analysis included patients with solid tumors of different types (Table 1) independent of stage and/or grade or treatment modality. Various treatment outcomes (see below) were compared between patients with high and low tumoral HIF- $2 \alpha$ expression. PubMed and Embase were used to identify studies that investigated the prognostic significance of HIF- $2 \alpha$ in solid tumors to be included in this meta-analysis. The search for literature was performed including papers published until February 1, 2018. Three main key words were identified to address the research question of this meta-analysis, i.e., prognosis, cancer, and HIF2. Several combinations of the selected keywords (in any of the formulations or truncations) were tested as free text searches to identify potential articles to be included in this meta-analysis (Supplementary File S1 in Supplementary Material). A total of 636 papers were identified from both databases (Figure 1).

TABLE 1 | Summary of results of subgroup meta-analyses of different organ sites.

\begin{tabular}{|c|c|c|c|c|c|c|}
\hline Organ site & Overall survival & Disease-free survival & $\begin{array}{c}\text { Disease-specific } \\
\text { survival }\end{array}$ & Locoregional control & $\begin{array}{c}\text { Metastasis-free } \\
\text { survival }\end{array}$ & $\begin{array}{c}\text { Progression-free } \\
\text { survival }\end{array}$ \\
\hline Bladder & & & & $0.51(0.33-0.77)^{\mathrm{a}}$ & & \\
\hline Brain & $3.78(1.64-8.75)^{a}$ & & & & & \\
\hline Breast & $1.18(0.95-1.47)$ & & $2.3(1.3-4.1)^{\mathrm{a}}$ & $1.6(1-2.4)^{a}$ & & \\
\hline Cartilage & $4.13(1.47-11.58)^{a}$ & & & & & \\
\hline Cervix & & & & $1.53(1.14-2.03)^{\mathrm{a}}$ & & \\
\hline Colorectal & $1.46(0.7-3.04)$ & $1.86(0.89-3.92)^{\mathrm{a}}$ & $0.8(0.61-1.05)^{\mathrm{a}}$ & $0.54(0.25-1.17)^{\mathrm{a}}$ & & \\
\hline Endometrium & $5.72(1.51-21.6)^{a}$ & & & & & \\
\hline Head and neck & 1.55 (1.24-1.92) & $1.41(0.99-2)$ & $1.45(0.8-2.64)$ & 1.94 (1.43-2.63) & & \\
\hline Kidney & $0.61(0.27-1.35)$ & & $1.21(0.57-2.6)$ & $0.54(0.11-2.57)$ & $0.08(0.03-0.27)^{\mathrm{a}}$ & $0.75(0.32-1.73)$ \\
\hline Liver & $1.06(0.43-2.61)$ & $1.52(0.82-2.84)^{\mathrm{a}}$ & & $1.22(0.87-1.83)^{\mathrm{a}}$ & & \\
\hline Lung & $2.15(1.65-2.81)$ & $8.47(3.26-22.06)^{\mathrm{a}}$ & & & & \\
\hline Ovarium & $2.72(1.27-5.83)^{a}$ & & & & & \\
\hline Pancreas & $2.11(1.38-3.24)$ & & & & & $1.67(1.26-2.21)^{a}$ \\
\hline Prostate & & & & & $2.44(1.07-5.57)^{a}$ & $2.94(1.99-4.36)^{\mathrm{a}}$ \\
\hline Salivary glands & $4.52(1.06-19.3)^{\mathrm{a}}$ & & & $3.64(0.72-18.42)^{a}$ & $3.36(0.89-12.66)^{\mathrm{a}}$ & \\
\hline Skin & $3.21(1.15-8.97)^{a}$ & & $3.81(1.66-8.78)^{a}$ & & & \\
\hline Soft tissues & & & $1.53(1.03-2.28)^{a}$ & & & \\
\hline Stomach & $1.7(1.25-2.32)$ & & $1.6(1-2.4)^{a}$ & & & \\
\hline
\end{tabular}

The hazard ratio (HR) with 95\% confidence interval is shown. Highlighted numbers indicate statistically significant association between hypoxia-inducible factor-2 $\alpha$ expression and prognosis $(p<0.05)$.

aWhen HR was available from only one paper, the values were adopted from that single paper (21-69). 


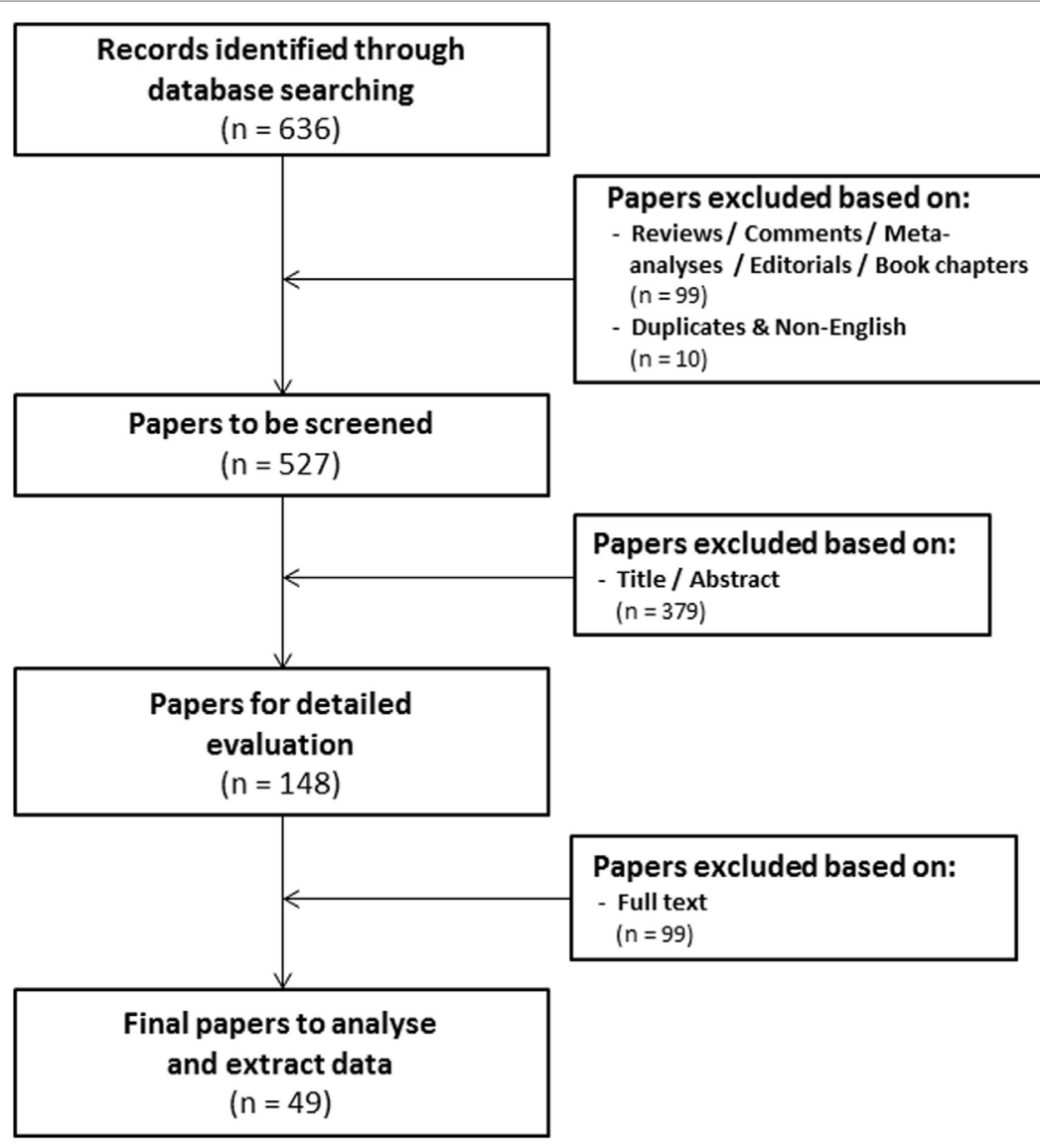

FIGURE 1 | Flowchart of selecting articles describing the association between tumoral hypoxia-inducible factor-2 $\alpha$ expression and prognosis.

\section{Screening of Papers}

Three independent reviewers assessed the eligibility of the studies. The first round of screening was based on the title and abstract (Eloy Moreno Roig and Arjan J. Groot). 99 review articles without original data, conference records, commentaries, meta-analyses, editorials, or book chapters were excluded, as were 10 overlapping or non-English papers. The total number of papers for further screening was thereby reduced to 527 (Figure 1). The second round consisted of a detailed evaluation of the full-text (Eloy Moreno Roig and Ala Yaromina).

In order to be included in the meta-analysis, a study had to fulfill predetermined inclusion/exclusion criteria: (1) only solid primary tumors of various types were included, (2) all endpoints were included with the minimal median follow-up of 1 year, (3) all treatments were included, (4) none of the patient populations were excluded by distinctive diagnosis, tumor grade, or tumor stage, and (5) pre-treatment protein expression by immunohistochemistry was the only technique for HIF- $2 \alpha$ detection included. Discrepancies between the included papers by both reviewers were discussed and consensus was reached on all. A total of 49 papers were included in the meta-analysis (Figure 1) (21-69).

\section{Data Extraction}

Reported parameters were extracted from each paper, i.e., the number and origin of patients, treatment modalities, tumor organ, tumor stage, tumor type, group dichotomization, antibody supplier, expression pattern, cellular localization, positivity in macrophages, and outcome variables (see below). The univariate hazard ratio (HR) and 95\% confidence interval (95\% CI) were directly obtained from the information available in the text. If not reported, the method from Tierney et al. was used to calculate $\mathrm{HR}$ and thereby assess prognostic value of HIF- $2 \alpha$ expression (70). Multivariate HR was only considered when the univariate HR could not be estimated. Authors were contacted to obtain additional data when not all the information was reported for estimating HR.

Kidney cancer was excluded from the main analysis because the loss of the VHL gene, a common mutation in CC-RCC, results in the stabilization of HIFs independent of oxygen, i.e., an alternative mechanism of HIF- $2 \alpha$ activation in cancer absent in the majority of other solid tumors (71). Therefore, prognostic value of HIF- $2 \alpha$ in this tumor type has been analyzed separately.

\section{Quality Assessment}

The methodological quality of the included papers was evaluated with an adjusted version of the Newcastle-Ottawa scale (NOS) to better suit the study design of the included papers (Supplementary File S2 in Supplementary Material) (72). The NOS was proposed in the 2011 version of the Cochrane Collaboration handbook being an easy method to evaluate the methodological quality of 
cohort studies (available at http://www.ohri.ca/programs/clinical_epidemiology/oxford.asp).

\section{Statistical Analysis and Sensitivity Analysis}

Distribution and frequencies of the extracted data parameters were analyzed using SPSS (version 22). Meta-analysis was performed using R statistical software with the Metafor Library (version 2.0-0) (73). Fixed-effect modeling was performed when no statistical significant heterogeneity between studies was observed. When the heterogeneity between studies was statistically significant $(p<0.05)$, random-effects modeling was applied based on the DerSimonian and Laird method (74). The inverse variance of each study was used to assign an independent weight value. Six different endpoints were considered for the analysis: overall survival (OS), disease-free survival (DFS), locoregional control (LC), disease-specific survival (DSS), metastasis-free survival (MFS), and progression-free survival (PFS). Sensitivity analysis was performed by analyzing subgroups of studies based on organ site. We assessed the possibility of publication bias and heterogeneity among studies by generating and visually analyzing funnel plots. Asymmetric funnel plots and studies outside the pyramid suggest heterogeneity between them.

\section{RESULTS}

This meta-analysis includes a total number of 6,052 patients across 49 independent studies (21-69). The median follow-up time ranged between 27 and 391 months and mostly included only a small number of patients (median 90, range 21-695). Selected papers were published between 2001 and 2017 of which 56\% were published after 2010. Depending on the study, patients followed different treatment schedules. In most of the selected studies, patients were treated with surgery alone (56\%), in combination with either chemotherapy $(8 \%)$ or standard radiotherapy $(10 \%)$, or a combination of all three modalities (14\%). Other treatment alternatives such as hormonal therapy and tyrosine-kinase inhibitors were used in $8 \%$ of the studies. Overall, the majority of the patients $(61 \%)$ were treated with surgery alone. Most studies report on head and neck and kidney cancer patients (both 18\%) followed by colon, liver, pancreas, and lung cancer patients (all of them $8 \%$ ). By contrast, cancers of the bladder, cartilage, cervix, endometrium, ovarian, and salivary glands were only described once.

Immunohistochemical staining of HIF- $2 \alpha$ was most commonly performed using the EP190b Ab (38\%) from Novus Biologicals. Other studies used anti-HIF $2 \alpha$ antibodies obtained from other suppliers. Cytoplasmic expression of HIF- $2 \alpha$ was described in $14 \%$ of the studies and $18 \%$ were positive in the nucleus. A combination of both positive cytoplasmic and nuclear staining was reported in $46 \%$ of the studies. HIF- $2 \alpha$ expression was quantified using different methods and patient stratification into groups with low and high tumoral HIF- $2 \alpha$ expression was performed using different thresholds. Taken together, $45 \%$ of the total tumors were classified as expressing high levels of HIF- $2 \alpha$. Also, $26 \%$ of these studies stated positive staining in macrophages.
Overall, patients suffering from tumors with high HIF- $2 \alpha$ expression had a worse treatment outcome (Figure 2). This association was significant for OS $(p<0.0001)$, DFS $(p=0.0057)$, DSS $(p=0.0249), \operatorname{MFS}(p=0.0061)$, and PFS $(p=0.0058)$. No association was found between HIF- $2 \alpha$ expression and LC ( $p=0.1281)$. Subgroup analyses based on tumor type and treatment option were not performed due to the low number of studies. Studies on renal cell cancer were eliminated from the overall HR estimation as HIF- $2 \alpha$ plays a different role in this cancer type (71). Funnel plots demonstrated systematic heterogeneity for almost all the endpoints. This can be due to publication bias, variation across the reports, or small number of studies (Figure S1 in Supplementary Material).

\section{Overall Survival}

A total of 38 from the selected 49 studies investigated the association between HIF- $2 \alpha$ and OS. All the necessary information to estimate the HR could not be obtained from two papers and were therefore not included in the analysis (Table S1 in Supplementary Material) $(21,23,24,26-31,33-35,37-39,41-43,45,46,48$, $49,51,52,54-57,59,60,62-69)$. Based on these studies, high HIF- $2 \alpha$ expression was statistically significantly associated with a decreased OS $(\mathrm{HR}=1.69,95 \%$ CI 1.39-2.06, $p<0.0001$, Figure 3). Subgroup analysis based on the different organ sites indicated a similar negative association between tumoral HIF- $2 \alpha$ expression and OS: head and neck $(\mathrm{HR}=1.55,95 \% \mathrm{CI} 1.24-1.92$, $p<0.0001)$, lung (HR $=2.15,95 \%$ CI 1.65-2.81, $p<0.0001)$, stomach $(\mathrm{HR}=1.71,95 \% \mathrm{CI} 1.25-2.32, p=0.0007)$, and pancreas $(\mathrm{HR}=2.11,95 \% \mathrm{CI} 1.38-3.24, p=0.0006)$. By contrast, no association between tumoral HIF- $2 \alpha$ expression and OS was observed for breast ( $\mathrm{HR}=1.18,95 \%$ CI $0.95-1.47, p=0.1225)$, colon $(\mathrm{HR}=1.46,95 \% \mathrm{CI} 0.7-3.07, p=3121)$, liver $(\mathrm{HR}=1.06$, $95 \%$ CI $0.43-2.61, p=0.89)$, and kidney $(\mathrm{HR}=0.61,95 \% \mathrm{CI}$ $0.27-1.35, p=0.2239$ ) cancer (Table 1 ).

\section{Disease-Free Survival}

Effect of pre-treatment expression of HIF- $2 \alpha$ on DFS could be evaluated in six studies $(36,37,54,66,67,69)$. Overall, high HIF$2 \alpha$ expression was significantly associated with a decreased DFS $(\mathrm{HR}=1.87,95 \%$ CI 1.2-2.92, $p=0.0057$, Figure 4). Subgroup

\begin{tabular}{|c|c|}
\hline & HR $(95 \% \mathrm{CI})$ \\
\hline OS & $1.69(1.39-2.06)$ \\
\hline DFS & $1.87(1.2-2.92)$ \\
\hline DSS & $1.57(1.06-2.34)$ \\
\hline $\mathbf{L C}$ & $1.31(0.92-1.86)$ \\
\hline MFS & $2.67(1.32-5.38)$ \\
\hline \multirow[t]{2}{*}{ PFS } & $2.18(1.25-3.78)$ \\
\hline & 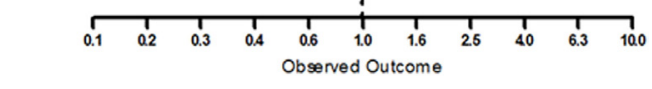 \\
\hline $\begin{array}{l}\text { FIGURE } 2 \\
\text { endpoints. } \\
\text { confidence }\end{array}$ & $\begin{array}{l}\text { Summary of the overall hazard ratios (HRs) for different } \\
\text { Symbols represent the HR and horizontal bars the 95\% } \\
\text { interval }(95 \% \mathrm{Cl})(21-69) \text {. }\end{array}$ \\
\hline
\end{tabular}




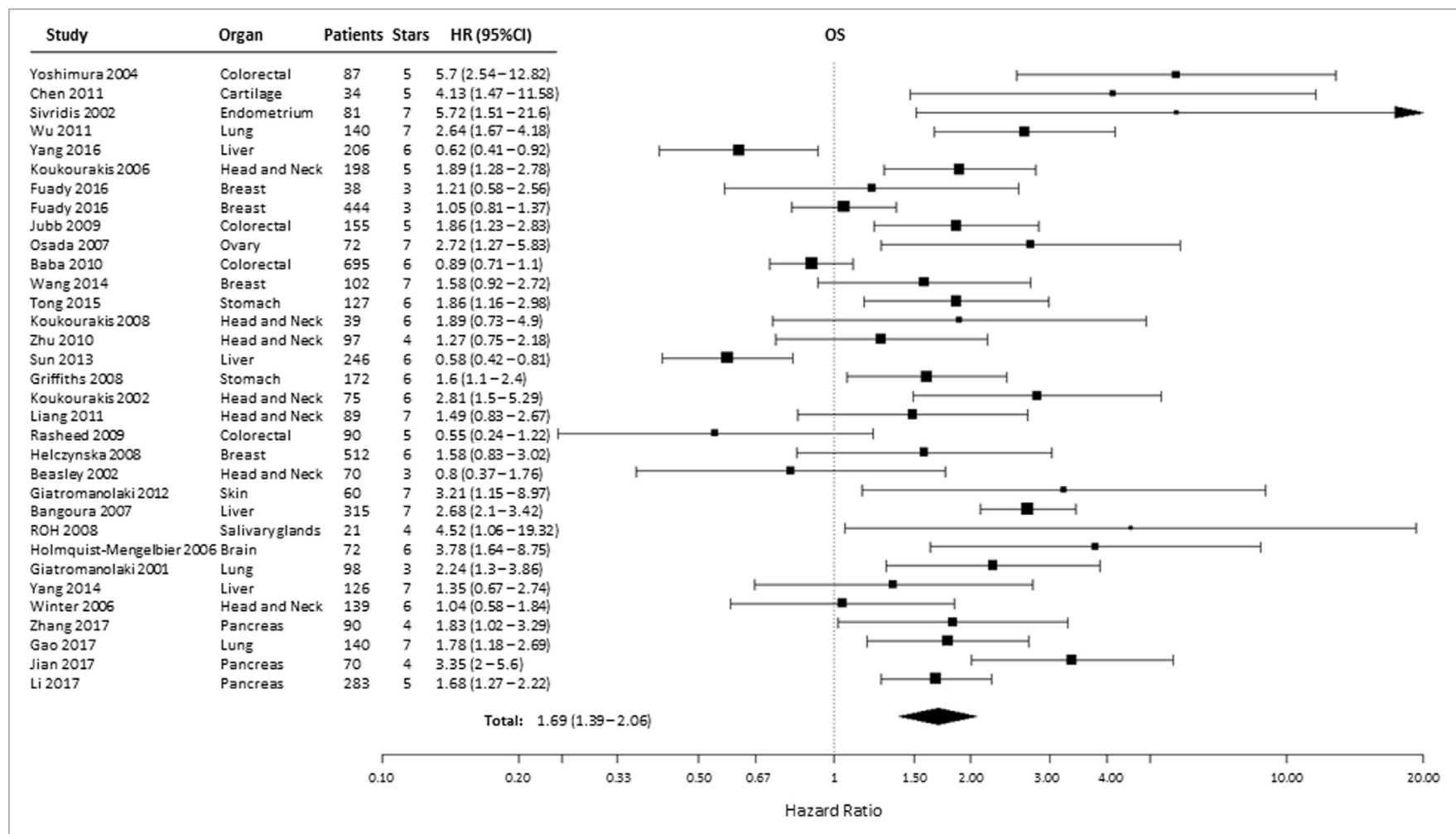

FIGURE 3 | Forest plot of hazard ratios (HRs) with 95\% confidence interval (95\% Cl) (horizontal bars) for the association of hypoxia-inducible factor-2 $\alpha$ expression and overall survival (OS). Symbol size represents the assigned weight of the study $(21,24,26,28,30,31,33-35,37,38,41-43,45,46,48,49,52,54-57,59,60$, 62-64, 66-69).

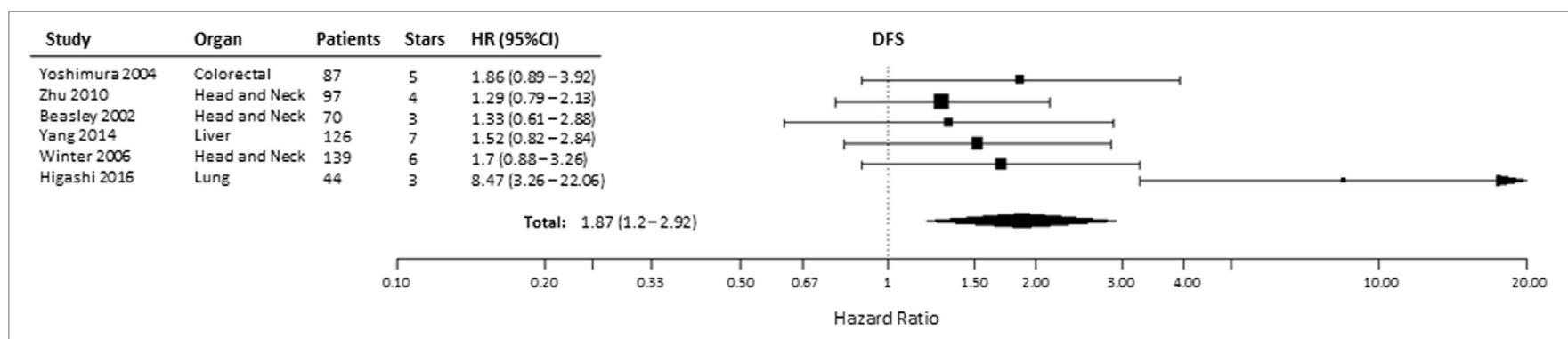

FIGURE 4 | Forest plot of hazard ratios (HRs) with 95\% confidence interval (95\% Cl) (horizontal bars) for the association between hypoxia-inducible factor-2 $\alpha$ expression and disease-free survival (DFS). Symbol size represents the assigned weight of the study $(36,37,54,66,67,69)$.

analysis indicated that elevated HIF- $2 \alpha$ levels were marginally significantly associated with DFS in head and neck cancer $(\mathrm{HR}=1.41,95 \%$ CI 0.99-2, $p=0.0577)$ (Table 1$)$.

\section{Disease-Specific Survival}

A total of 12 studies evaluated the association of HIF- $2 \alpha$ expression with DSS, of which 2 studies provided incomplete data to estimate the HR (Table S1 in Supplementary Material) and 3 were excluded for being CC-RCC. In the remaining seven studies, patients suffering from tumors with high HIF- $2 \alpha$ had significantly shorter DSS ( $\mathrm{HR}=1.57,95 \%$ CI 1.06-2.34, $p=0.0249$, Figure 5) $(24,25,32,34,35,47,49,50,53,58,61,66)$. Subgroup analysis by organ site revealed not association between high HIF- $2 \alpha$ expression and worse DSS in tumors of the head and neck $(\mathrm{HR}=1.45$, 95\% CI $0.8-2.64, p=0.2219)$ and kidney $(\mathrm{HR}=1.21,95 \% \mathrm{CI}$ $0.57-2.6, p=0.6138$ ) cancer (Table 1).

\section{Locoregional Control}

Ten studies were included to analyze the association of HIF- $2 \alpha$ expression with risk of LC. High tumoral HIF- $2 \alpha$ expression was not associated with a higher risk of locoregional recurrences compared with patients with low expression of HIF-2 $\alpha$ in tumors $(\mathrm{HR}=1.31,95 \% \mathrm{CI} 0.92-1.86, p=0.1281$, Figure 6) $(35,40,44-46,52,56-59)$. However, subgroup analysis for the 


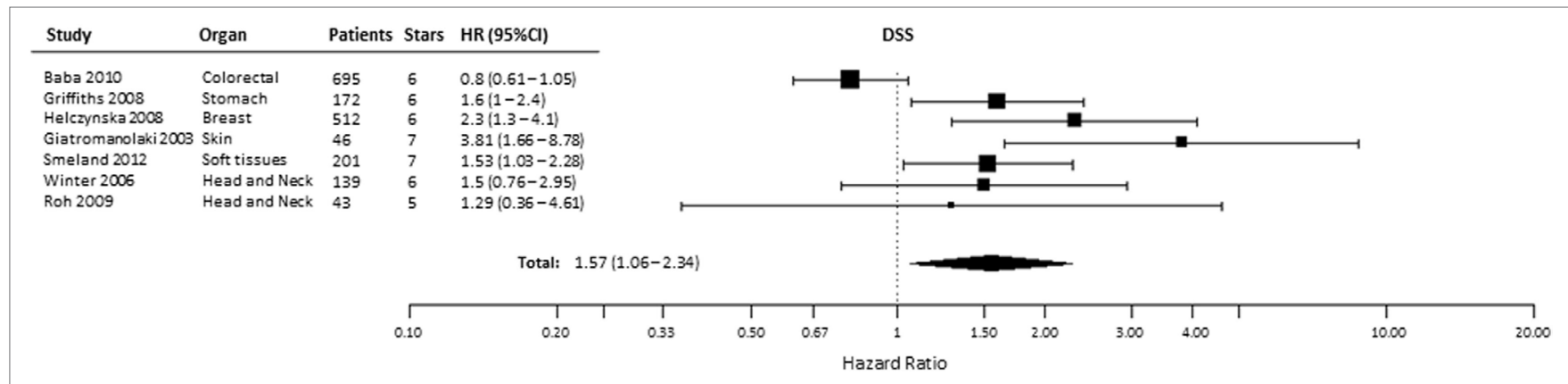

FIGURE 5 | Forest plot of hazard ratios (HRs) with 95\% confidence interval (95\% Cl) (horizontal bars) for the association between hypoxia-inducible factor-2 $\alpha$ expression and disease-specific survival (DSS). Symbol size represents the assigned weight of the study $(24,32,34,35,58,61,66)$.

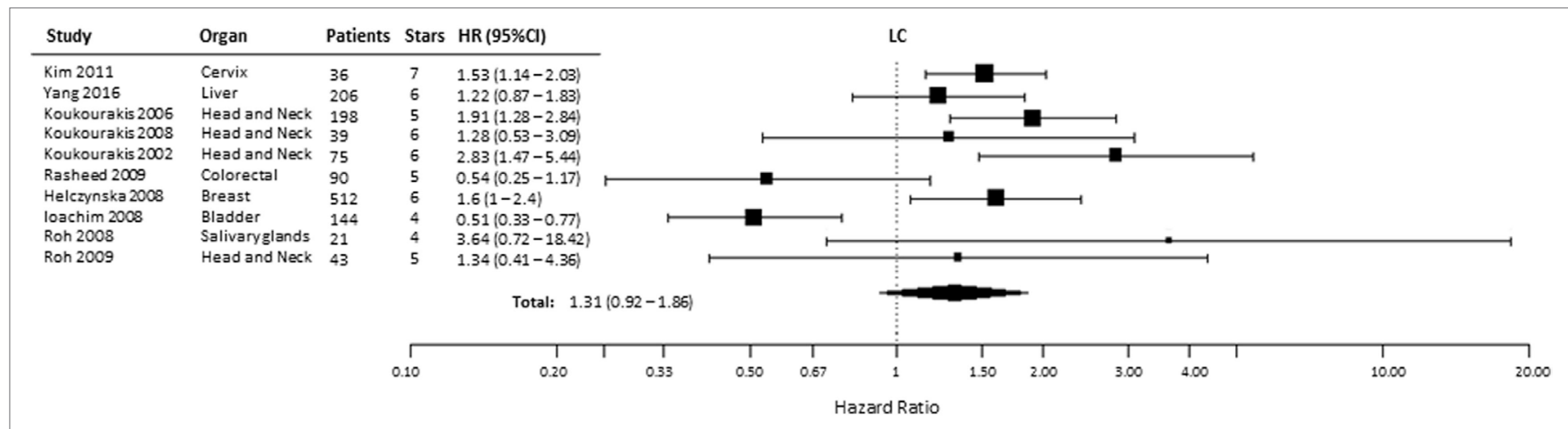

FIGURE 6 | Forest plot of hazard ratios (HRs) with 95\% confidence interval (95\% Cl) (horizontal bars) for the association between hypoxia-inducible factor-2 $\alpha$ expression and locoregional control (LC). Symbol size represents the assigned weight of the study (35, 40, 44-46, 52, 56-59).

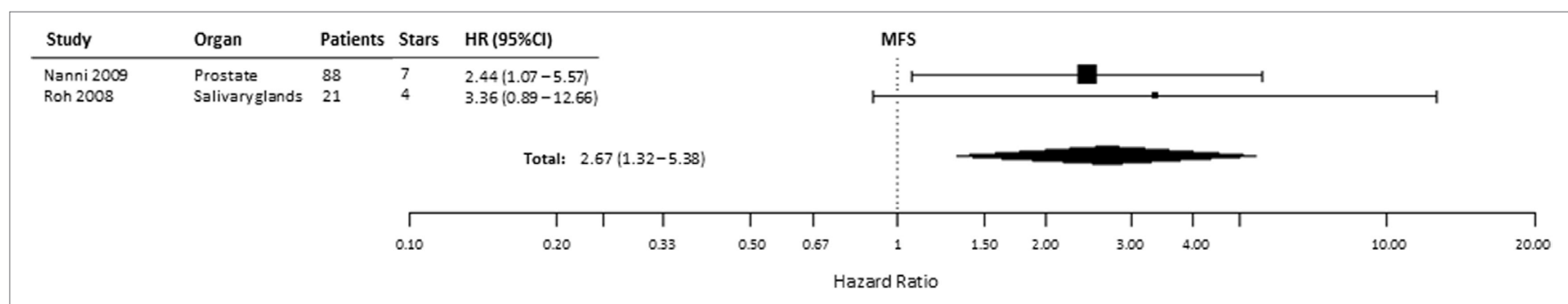

FIGURE 7 | Forest plot of hazard ratios (HRs) with 95\% confidence interval (95\% Cl) (horizontal bars) for the association between hypoxia-inducible factor-2 $\alpha$ expression and metastasis-free survival (MFS). Symbol size represents the assigned weight of the study $(53,57)$.

association between high HIF-2 $\alpha$ expression in tumors and worse LC was significant in head and neck tumors ( $\mathrm{HR}=1.94,95 \% \mathrm{CI}$ 1.43-2.63, $p<0.0001)$. No significant association was observed in kidney tumors $(\mathrm{HR}=0.54,95 \%$ CI $0.11-2.57, p=0.4409)$ (Table 1).

\section{Metastasis-Free Survival}

Based on the available data reported in two studies, we analyzed the relationship of HIF-2 $\alpha$ expression with MFS $(53,57)$. We found that the pooled HR for MFS was 2.67 (95\% CI 1.32-5.38, $p=0.0061$ ), indicating that HIF2 $\alpha$ expression is a negative prognostic factor for MFS in patients with prostate and salivary gland cancer (Figure 7). In kidney cancer, one paper reported an inverse correlation between HIF- $2 \alpha$ positivity and MFS (HR $=0.08,95 \%$ CI $0.03-0.27, p<0.001)(23)$.

\section{Progression-Free Survival}

Progression-free survival was reported in 5 of 49 included studies, of which 1 study provided incomplete data (Table S1 in Supplementary Material) and 2 described patients with renal cell cancer $(29,39,48,51,53)$. Similar to the other endpoints, PFS was significantly shorter $(\mathrm{HR}=2.18,95 \%$ CI $1.25-3.78, p=0.0058)$ in patients with tumors expressing high levels of HIF- $2 \alpha$ (Figure 8). In kidney cancers, these data showed no association between 


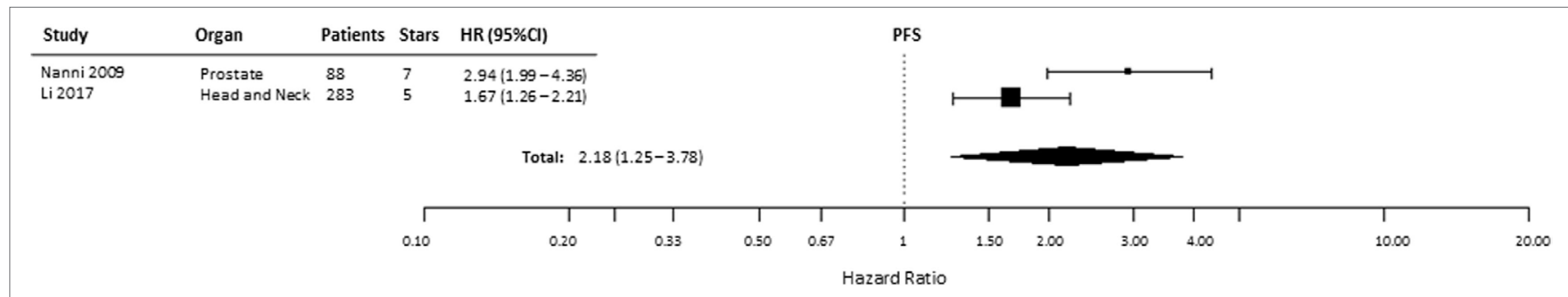

FIGURE 8 | Forest plot of hazard ratios (HRs) with 95\% confidence interval (95\% Cl) (horizontal bars) for the association between hypoxia-inducible factor-2 $\alpha$ expression and progression-free survival (PFS). Symbol size represents the assigned weight of the study $(48,53)$.

HIF- $2 \alpha$ expression and PFS $(\mathrm{HR}=0.75,95 \%$ CI $0.32-1.72$, $p=0.498)$ (Table 1).

\section{High-Quality Papers}

This meta-analysis used an adjusted version of the NOS to evaluate the quality of a study. The scores of this quality assessment ranged between 1 and 7 stars, i.e., the maximum, awarded per study. Approximately $78 \%$ of these studies were considered as highquality studies, i.e., with a number of stars greater or equal to 5 .

\section{DISCUSSION}

There is growing evidence that overexpression of HIF- $2 \alpha$ in cancer can contribute to differences in treatment outcome between patients. Although HIF- $2 \alpha$ oncogenic activity has been proven, there is significant variability in its value as a biomarker for patient's prognosis. In view of its role in regulating oncogenic processes triggered by hypoxia, the evaluation of its prognostic value in cancer is of great clinical importance, which may lead to a more accurate patient prognosis and the generation of targeted therapies in the future. This meta-analysis is the first complete overview to summarize all reported clinical studies investigating the impact of HIF- $2 \alpha$ expression on treatment outcome in solid tumors.

Here, we show that high HIF- $2 \alpha$ levels in cancer are correlated with worse prognosis for OS, DFS, DSS, MFS, and PFS. No association between HIF-2 $\alpha$ expression and LC was found. These data suggest that HIF- $2 \alpha$ might not be involved in treatment resistance directly but is indicative of more malignant phenotype with greater metastatic potential. Subgroup analyses were performed to explore the source of heterogeneity based on different organ sites. We found that this variable did not alter the prognostic value of HIF- $2 \alpha$ for most of the endpoints assessed.

We excluded CC-RCCs from the main analysis due to a different regulatory mechanism of HIF- $2 \alpha$, which might affect the final outcome. A common mutation in CC-RCC is the loss of the VHL gene, which results in the stabilization of HIFs upon normoxia. This oncogenic process is specific for CC-RCC with an abundance of $80 \%$ in patients, resulting in an alternative mechanism of HIF$2 \alpha$ activation in cancer (71). However, the negative prognostic value of HIF- $2 \alpha$ does not change when CC-RCC is included in the overall meta-analysis (data not shown). In CC-RCC, we found that HIF- $2 \alpha$ is a positive prognostic biomarker for MFS only (Table 1). Subcellular localization might also affect the prognostic significance of HIF-2 $\alpha$ in CC-RCC as previously noted (75). Their data show that high cytoplasmic expression of HIF- $2 \alpha$ was significantly associated with poor DSS which is consistent with our findings. By contrast, high nuclear expression of HIF- $2 \alpha$ is associated with better DSS in patients (Table S2 in Supplementary Material). Therefore, it might be that subcellular localization of HIF- $2 \alpha$ is crucial in determining the prognostic value in CC-RCC patients, which requires further investigation. Another study demonstrated that HIF- $2 \alpha$ can be used as a predictive biomarker related to drug selection for CC-RCC patients treated with sunitinib and sorafenib (51). Therefore, assessment of subgroup categories is necessary to better evaluate the prognostic and predictive value of HIF- $2 \alpha$ in CC-RCC.

Previous studies have shown that increased infiltration of tumor-associated macrophages (TAMs) in cancer patients is associated with worse OS (76). In comparison with normal macrophages, TAMs express high levels of HIF-2 $\alpha$, which seems to be an indicator of poor prognosis in cancer patients (77). Using in vivo models of acute inflammation, it has been shown that HIF- $2 \alpha$ expression in macrophages is essential for inflammatory responses by regulating proinflammatory cytokine expression (78). Together, these studies show that HIF- $2 \alpha$ tightly regulates macrophage functions, which in turn may impact the patient prognosis. We excluded studies in which only macrophage data were reported, since the main goal of this meta-analysis is to determine the prognostic role of HIF- $2 \alpha$ expression in tumor cells. To note, $26 \%$ of the studies included in this meta-analysis stated HIF- $2 \alpha$ reactivity in macrophages together with tumor cells.

The papers included in this meta-analysis were all published between 2001 and 2018, which is likely attributed to the fact that HIF- $2 \alpha$ was first identified by independent groups a few years earlier $(79,80)$. First studies showed the importance of HIF- $2 \alpha$ on the transcription of hypoxia-regulated genes such as VEGF in endothelial cells, fibroblasts, and epithelial cells. In addition, researchers described the novel role of HIF- $2 \alpha$ in comparison with the already studied HIF-1 $\alpha$, its counteractive protein, in hypoxia and tissue homeostasis (80-83). The discovery of this new hypoxia-activated transcription factor encouraged research to further evaluate the role of HIF- $2 \alpha$ in vivo and during development in mice. Their data show that HIF- $2 \alpha$ displays a specific pattern of developmental expression at different embryonic stages (84). HIF- $2 \alpha$ was thereby defined as a novel bHLH-PAS protein involved in the response to hypoxia 
showing overlapping but also independent roles with HIF-1 $\alpha$. Basic HLH (helix-loop-helix)-PER-ARNT-SIM (bHLH-PAS) proteins are a family of transcription factors, which respond to environmental signals such as low oxygen levels. This family of proteins is involved in dimerization, DNA binding, and signal transduction (85). Future studies demonstrated that HIF-2 $\alpha$ was expressed in a much larger number of cell types (86). Apart from its regulatory role in normal tissue homeostasis, HIF- $2 \alpha$ was seen to be commonly upregulated in a broad range of cancers and to contribute to multiple aspects of tumorigenesis such as altered metabolism, angiogenesis, epithelial-mesenchymal transition, and metastasis. This is supported by data showing that HIF- $2 \alpha$ is involved in promoting resistance of tumor cells to several treatment modalities and increased patient mortality (87). The important role of HIF- $2 \alpha$ in cancer prognosis is also supported by the results of this meta-analysis, which shows that patients with high HIF- $2 \alpha$ expression have shorter OS. HIF- $1 \alpha$ protein, in turn, has been shown to induce more aggressive phenotype in tumors cells by regulating similar cellular mechanisms (88). Therefore, assessment of oxygen-sensing proteins in tumors prior and/or during therapy may represent a powerful prognostic and predictive biomarker as well as important targets for new anticancer treatments, which warrants further investigations.

Importantly, there is also the risk of encountering publication bias since positive results are more likely to be published than negative ones. This meta-analysis identified a total of 49 studies of which 4 could not be included in final analysis because the HR could not be estimated due to incomplete reporting. Three of four studies stated non-significant association between HIF- $2 \alpha$ and outcome (Table S1 in Supplementary Material). Including these four papers in the analysis might therefore decrease the magnitude of the prognostic value of HIF- $2 \alpha$ expression reported here. Nevertheless, since the prognostic value of HIF- $2 \alpha$ expression is highly statistically significant and the number of excluded studies is very low, we believe that the possible effect of publication bias on this association is negligible.

There are also other limitations in this meta-analysis. The approach of extrapolating the HRs could potentially introduce the source of bias. First, when it was not possible to extract HR directly from the article, survival curves were used to extract data to estimate HR following the method of Tierney et al. (70). Second, significant heterogeneity was found for most of the endpoints tested, which might confirm the high variability

\section{REFERENCES}

1. Vaupel P, Mayer A. Hypoxia in cancer: significance and impact on clinical outcome. Cancer Metastasis Rev (2007) 26(2):225-39. doi:10.1007/s10555007-9055-1

2. Gort EH, Groot AJ, van der Wall E, van Diest PJ, Vooijs MA. Hypoxic regulation of metastasis via hypoxia-inducible factors. Curr Mol Med (2008) 8(1):60-7. doi:10.2174/156652408783565568

3. Rockwell S, Dobrucki IT, Kim EY, Marrison ST, Vu VT. Hypoxia and radiation therapy: past history, ongoing research, and future promise. Curr Mol Med (2009) 9(4):442-58. doi:10.2174/156652409788167087

4. Walsh JC, Lebedev A, Aten E, Madsen K, Marciano L, Kolb HC. The clinical importance of assessing tumor hypoxia: relationship of tumor hypoxia to prognosis and therapeutic opportunities. Antioxid Redox Signal (2014) 21(10):1516-54. doi:10.1089/ars.2013.5378 among studies. Reduced variability could be achieved by better stratifying tumors into high and low expressing. Third, the use of different antibodies with varying dilutions to detect HIF- $2 \alpha$, different staining protocols, different scoring methods, subcellular localization, and cutoff values may contribute to heterogeneity. Finally, due to the lack of papers referring to each specific endpoint, treatment modality, and/or organ site, it is difficult to set a robust outcome and achieve significant data for different subgroups. Therefore, more high-quality, large-sample, prospectively designed studies are needed to strengthen the prognostic and predictive relevance of HIF- $2 \alpha$ in solid cancers.

The results presented here clearly indicate that HIF- $2 \alpha$ expression is associated with worse prognosis in a global patient population and in some tumor sites. Altogether, the results of this metaanalysis support the development of a clinical test to determine patient prognosis and/or predict treatment outcome based on HIF- $2 \alpha$ expression, although standardized protocols remains to be developed and validated. While potent inhibitors targeting HIF- $2 \alpha$ are being translated into clinical trials for renal cancer (89) such predictive tests would be crucial in advancing antiHIF2 inhibitors not only in renal cancer but also in other solid cancers.

\section{AUTHOR CONTRIBUTIONS}

Study was conceived and designed by ER, AY, and MV. Screening of papers and data extraction was performed by ER, AY, and AG. Statistical analyses were performed by RH. Writing of the first draft of the manuscript was performed by ER. AY, RH, AG, LD, and MV contributed to the writing of the manuscript.

\section{FUNDING}

This work was supported by a H2020 grant from the European Research Council (ERC-CoG, 617060) and the Kankeronderzoekfonds Limburg from the Health Foundation Limburg.

\section{SUPPLEMENTARY MATERIAL}

The Supplementary Material for this article can be found online at https://www.frontiersin.org/articles/10.3389/fonc.2018.00224/ full\#supplementary-material.

5. Dubois LJ, Niemans R, van Kuijk SJ, Panth KM, Parvathaneni NK, Peeters SG, et al. New ways to image and target tumour hypoxia and its molecular responses. Radiother Oncol (2015) 116(3):352-7. doi:10.1016/j. radonc.2015.08.022

6. Hammond EM, Asselin MC, Forster D, O’Connor JP, Senra JM, Williams KJ. The meaning, measurement and modification of hypoxia in the laboratory and the clinic. Clin Oncol (R Coll Radiol) (2014) 26(5):277-88. doi:10.1016/j.clon.2014.02.002

7. Pettersen EO, Ebbesen P, Gieling RG, Williams KJ, Dubois L, Lambin P, et al. Targeting tumour hypoxia to prevent cancer metastasis. From biology, biosensing and technology to drug development: the METOXIA consortium. J Enzyme Inhib Med Chem (2015) 30(5):689-721. doi:10.3109/14756366.201 4.966704

8. Yaromina A, Granzier M, Biemans R, Lieuwes N, van Elmpt W, Shakirin G, et al. A novel concept for tumour targeting with radiation: inverse 
dose-painting or targeting the "low drug uptake volume". Radiother Oncol (2017) 124(3):513-20. doi:10.1016/j.radonc.2017.04.020

9. Eales KL, Hollinshead KE, Tennant DA. Hypoxia and metabolic adaptation of cancer cells. Oncogenesis (2016) 5:e190. doi:10.1038/oncsis.2015.50

10. Wouters BG, Koritzinsky M. Hypoxia signalling through mTOR and the unfolded protein response in cancer. Nat Rev Cancer (2008) 8(11):851-64. doi: $10.1038 / \mathrm{nrc} 2501$

11. Ke Q, Costa M. Hypoxia-inducible factor-1 (HIF-1). Mol Pharmacol (2006) 70(5):1469-80. doi:10.1124/mol.106.027029

12. Akeno N, Czyzyk-Krzeska MF, Gross TS, Clemens TL. Hypoxia induces vascular endothelial growth factor gene transcription in human osteoblast-like cells through the hypoxia-inducible factor-2alpha. Endocrinology (2001) 142(2):959-62. doi:10.1210/endo.142.2.8112

13. Carroll VA, Ashcroft M. Role of hypoxia-inducible factor (HIF)-1alpha versus HIF-2alpha in the regulation of HIF target genes in response to hypoxia, insulin-like growth factor-I, or loss of von Hippel-Lindau function: implications for targeting the HIF pathway. Cancer Res (2006) 66(12):6264-70. doi:10.1158/0008-5472.CAN-05-2519

14. Shah T, Krishnamachary B, Wildes F, Mironchik Y, Kakkad SM, Jacob D, et al. HIF isoforms have divergent effects on invasion, metastasis, metabolism and formation of lipid droplets. Oncotarget (2015) 6(29):28104-19. doi:10.18632/ oncotarget. 4612

15. Imamura T, Kikuchi H, Herraiz MT, Park DY, Mizukami Y, MinoKenduson M, et al. HIF-1alpha and HIF-2alpha have divergent roles in colon cancer. Int J Cancer (2009) 124(4):763-71. doi:10.1002/ijc.24032

16. Wigerup C, Pahlman S, Bexell D. Therapeutic targeting of hypoxia and hypoxia-inducible factors in cancer. Pharmacol Ther (2016) 164:152-69. doi:10.1016/j.pharmthera.2016.04.009

17. Bertout JA, Majmundar AJ, Gordan JD, Lam JC, Ditsworth D, Keith B, et al. HIF $2 \alpha$ inhibition promotes $\mathrm{p} 53$ pathway activity, tumor cell death, and radiation responses. Proc Natl Acad Sci U S A (2009) 106(34):14391-6. doi:10.1073/ pnas. 0907357106

18. Li Y, Li C, Shi H, Lou L, Liu P. The association between the rs 11549465 polymorphism in the hif-1alpha gene and cancer risk: a meta-analysis. Int J Clin Exp Med (2015) 8(2):1561-74.

19. Ren HY, Zhang YH, Li HY, Xie T, Sun LL, Zhu T, et al. Prognostic role of hypoxia-inducible factor-1 alpha expression in osteosarcoma: a meta-analysis. Onco Targets Ther (2016) 9:1477-87. doi:10.2147/OTT.S95490

20. Zheng SS, Chen XH, Yin X, Zhang BH. Prognostic significance of HIF-1alpha expression in hepatocellular carcinoma: a meta-analysis. PLoS One (2013) 8(6):e65753. doi:10.1371/journal.pone.0065753

21. Wu XH, Qian C, Yuan K. Correlations of hypoxia-inducible factor-1 $1 \alpha /$ hypoxia-inducible factor-2 $\alpha$ expression with angiogenesis factors expression and prognosis in non-small cell lung cancer. Chin Med J (2011) 124(1):11-8.

22. Abel EJ, Bauman TM, Weiker M, Shi F, Downs TM, Jarrard DF, et al. Analysis and validation of tissue biomarkers for renal cell carcinoma using automated high-throughput evaluation of protein expression. Hum Pathol (2014) 45(5):1092-9. doi:10.1016/j.humpath.2014.01.008

23. Szendrői A, Szász AM, Kardos M, Tőkés AM, Idan R, Szűcs M, et al. Opposite prognostic roles of HIFla and HIF2a expressions in bone metastatic clear cell renal cell cancer. Oncotarget (2016) 7(27):42086-98. doi:10.18632/ oncotarget.9669

24. Baba Y, Nosho K, Shima K, Irahara N, Chan AT, Meyerhardt JA, et al. HIF1A overexpression is associated with poor prognosis in a cohort of 731 colorectal cancers. Am J Pathol (2010) 176(5):2292-301. doi:10.2353/ajpath.2010.090972

25. Biswas S, Charlesworth PJ, Turner GD, Leek R, Thamboo PT, Campo L, et al. CD31 angiogenesis and combined expression of HIF-1alpha and HIF-2alpha are prognostic in primary clear-cell renal cell carcinoma (CC-RCC), but HIFalpha transcriptional products are not: implications for antiangiogenic trials and HIFalpha biomarker studies in primary CC-RCC. Carcinogenesis (2012) 33(9):1717-25. doi:10.1093/carcin/bgs222

26. Chen C, Ma Q, Ma X, Liu Z, Liu X. Association of elevated HIF-2alpha levels with low Beclin 1 expression and poor prognosis in patients with chondrosarcoma. Ann Surg Oncol (2011) 18(8):2364-72. doi:10.1245/s10434-011$1587-5$

27. Ebru T, Fulya OP, Hakan A, Vuslat YC, Necdet S, Nuray C, et al. Analysis of various potential prognostic markers and survival data in clear cell renal cell carcinoma. Int Braz J Urol (2017) 43(3):440-54. doi:10.1590/S1677-5538. IBJU.2015.0521
28. Gao ZJ, Wang Y, Yuan WD, Yuan JQ, Yuan K. HIF-2alpha not HIF-1alpha overexpression confers poor prognosis in non-small cell lung cancer. Tumour Biol (2017) 39(6):1010428317709637. doi:10.1177/1010428317709637

29. Garcia-Donas J, Leandro-Garcia LJ, Gonzalez Del Alba A, Morente M, Alemany I, Esteban E, et al. Prospective study assessing hypoxia-related proteins as markers for the outcome of treatment with sunitinib in advanced clear-cell renal cell carcinoma. Ann Oncol (2013) 24(9):2409-14. doi:10.1093/ annonc/mdt219

30. Bangoura G, Liu ZS, Qian Q, Jiang CQ, Yang GF, Jing S. Prognostic significance of HIF-2alpha EPAS1 expression in hepatocellular carcinoma. World J Gastroenterol (2007) 13(23):3176-82. doi:10.3748/wjg.v13.i23.3176

31. Giatromanolaki A, Sivridis E, Bechrakis NE, Willerding G, St Charitoudis G, Foerster MH, et al. Phosphorylated pVEGFR2/KDR receptor expression in uveal melanomas: relation with HIF2alpha and survival. Clin Exp Metastasis (2012) 29(1):11-7. doi:10.1007/s10585-011-9424-6

32. Giatromanolaki A, Sivridis E, Kouskoukis C, Gatter KC, Harris AL, Koukourakis MI. Hypoxia-inducible factors 1alpha and 2alpha are related to vascular endothelial growth factor expression and a poorer prognosis in nodular malignant melanomas of the skin. Melanoma Res (2003) 13(5):493-501. doi:10.1097/00008390-200310000-00008

33. Giatromanolaki A, Koukourakis MI, Sivridis E, Turley H, Talks K, Pezzella F, et al. Relation of hypoxia inducible factor 1 alpha and 2 alpha in operable non-small cell lung cancer to angiogenic/molecular profile of tumours and survival. Br J Cancer (2001) 85(6):881-90. doi:10.1054/bjoc.2001.2018

34. Griffiths EA, Pritchard SA, McGrath SM, Valentine HR, Price PM, Welch IM, et al. Hypoxia-associated markers in gastric carcinogenesis and HIF-2alpha in gastric and gastro-oesophageal cancer prognosis. Br J Cancer (2008) 98(5):965-73. doi:10.1038/sj.bjc.6604210

35. Helczynska K, Larsson AM, Holmquist-Mengelbier L, Bridges E, Fredlund E, Borgquist S, et al. Hypoxia-inducible factor-2alpha correlates to distant recurrence and poor outcome in invasive breast cancer. Cancer Res (2008) 68(22):9212-20. doi:10.1158/0008-5472.CAN-08-1135

36. Higashi K, Yamagishi T, Ueda Y, Ishigaki Y, Shimasaki M, Nakamura Y, et al. Correlation of HIF-1alpha/HIF-2alpha expression with FDG uptake in lung adenocarcinoma. Ann Nucl Med (2016) 30(10):708-15. doi:10.1007/ s12149-016-1116-5

37. Yoshimura H, Dhar DK, Kohno H, Kubota H, Fujii T, Ueda S, et al. Prognostic impact of hypoxia-inducible factors 1alpha and 2alpha in colorectal cancer patients: correlation with tumor angiogenesis and cyclooxygenase-2 expression. Clin Cancer Res (2004) 10(24):8554-60. doi:10.1158/1078-0432. CCR-0946-03

38. Holmquist-Mengelbier L, Fredlund E, Lofstedt T, Noguera R, Navarro S, Nilsson H, et al. Recruitment of HIF-1alpha and HIF-2alpha to common target genes is differentially regulated in neuroblastoma: HIF-2alpha promotes an aggressive phenotype. Cancer Cell (2006) 10(5):413-23. doi:10.1016/j. ccr.2006.08.026

39. Hui EP, Chan AT, Pezzella F, Turley H, To KF, Poon TC, et al. Coexpression of hypoxia-inducible factors 1alpha and 2alpha, carbonic anhydrase IX, and vascular endothelial growth factor in nasopharyngeal carcinoma and relationship to survival. Clin Cancer Res (2002) 8(8):2595-604.

40. Ioachim E, Michael M, Salmas M, Michael MM, Stavropoulos NE, MalamouMitsi V. Hypoxia-inducible factors HIF-1alpha and HIF-2alpha expression in bladder cancer and their associations with other angiogenesis-related proteins. Urol Int (2006) 77(3):255-63. doi:10.1159/000094819

41. Fuady JH, Gutsche K, Santambrogio S, Varga Z, Hoogewijs D, Wenger R. Estrogen-dependent downregulation of hypoxia-inducible factor (HIF)-2 $\alpha$ in invasive breast cancer cells. Oncotarget (2016). doi:10.18632/oncotarget.8866

42. Yang J, Zhu DM, Zhou XG, Yin N, Zhang Y, Zhang ZX, et al. HIF-2 $\alpha$ promotes the formation of vasculogenic mimicry in pancreatic cancer by regulating the binding of Twistl to the VE-cadherin promoter. Oncotarget (2017) 8(29):47801-15. doi:10.18632/oncotarget.17999

43. Jubb AM, Turley H, Moeller HC, Steers G, Han C, Li JL, et al. Expression of delta-like ligand 4 (Dll4) and markers of hypoxia in colon cancer. Br J Cancer (2009) 101(10):1749-57. doi:10.1038/sj.bjc.6605368

44. Kim MK, Kim TJ, Sung CO, Choi CH, Lee JW, Bae DS, et al. Clinical significance of HIF-2alpha immunostaining area in radioresistant cervical cancer. J Gynecol Oncol (2011) 22(1):44-8. doi:10.3802/jgo.2011.22.1.44

45. Koukourakis MI, Bentzen SM, Giatromanolaki A, Wilson GD, Daley FM, Saunders MI, et al. Endogenous markers of two separate hypoxia response 
pathways (hypoxia inducible factor 2 alpha and carbonic anhydrase 9) are associated with radiotherapy failure in head and neck cancer patients recruited in the CHART randomized trial. J Clin Oncol (2006) 24(5):727-35. doi:10.1200/JCO.2005.02.7474

46. Koukourakis MI, Giatromanolaki A, Danielidis V, Sivridis E. Hypoxia inducible factor (HIf1alpha and HIF2alpha) and carbonic anhydrase 9 (CA9) expression and response of head-neck cancer to hypofractionated and accelerated radiotherapy. Int J Radiat Biol (2008) 84(1):47-52. doi:10.1080/09553000701616114

47. Kroeger N, Seligson DB, Signoretti S, Yu H, Magyar CE, Huang J, et al. Poor prognosis and advanced clinicopathological features of clear cell renal cell carcinoma (ccRCC) are associated with cytoplasmic subcellular localisation of hypoxia inducible factor-2alpha. Eur JCancer (2014) 50(8):1531-40. doi:10.1016/j.ejca.2014.01.031

48. Li W, Chen C, Zhao X, Ye H, Zhao Y, Fu Z, et al. HIF-2alpha regulates non-canonical glutamine metabolism via activation of PI3K/mTORC2 pathway in human pancreatic ductal adenocarcinoma. J Cell Mol Med (2017) 21(11):2896-908. doi:10.1111/jcmm.13202

49. Liang X, Zheng M, Jiang J, Zhu G, Yang J, Tang Y. Hypoxia-inducible factor-1 alpha, in association with TWIST2 and SNIP1, is a critical prognostic factor in patients with tongue squamous cell carcinoma. Oral Oncol (2011) 47(2):92-7. doi:10.1016/j.oraloncology.2010.11.014

50. Liu Y, Tan X, Liu W, Chen X, Hou X, Shen D, et al. Follistatin-like protein 1 plays a tumor suppressor role in clear-cell renal cell carcinoma. Chin J Cancer (2018) 37(1):2. doi:10.1186/s40880-018-0267-2

51. Ma X, Wang L, Li H, Zhang Y, Gao Y, Guo G, et al. Predictive immunohistochemical markers related to drug selection for patients treated with sunitinib or sorafenib for metastatic renal cell cancer. Sci Rep (2016) 6:30886. doi:10.1038/srep30886

52. Koukourakis MI, Giatromanolaki A, Sivridis E, Simopoulos C, Turley H, Talks K, et al. Hypoxia-inducible factor (HIF1A and HIF2A), angiogenesis, and chemoradiotherapy outcome of squamous cell head-and-neck cancer. Clin Invest (2002) 53(5):1192-202.

53. Nanni S, Benvenuti V, Grasselli A, Priolo C, Aiello A, Mattiussi S, et al. Endothelial NOS, estrogen receptor beta, and HIFs cooperate in the activation of a prognostic transcriptional pattern in aggressive human prostate cancer. J Clin Invest (2009) 119(5):1093-108. doi:10.1172/JCI35079

54. Beasley NJP, Leek R, Alam M, Turley H, Cox GJ, Gatter K, et al. Hypoxiainducible factors HIF1 and HIF2 in head and neck cancer. Cancer Res (2002) 59(1):67-71.

55. Osada R, Horiuchi A, Kikuchi N, Yoshida J, Hayashi A, Ota M, et al. Expression of hypoxia-inducible factor 1alpha, hypoxia-inducible factor 2alpha, and von Hippel-Lindau protein in epithelial ovarian neoplasms and allelic loss of von Hippel-Lindau gene: nuclear expression of hypoxia-inducible factor lalpha is an independent prognostic factor in ovarian carcinoma. Hum Pathol (2007) 38(9):1310-20. doi:10.1016/j.humpath.2007.02.010

56. Rasheed S, Harris AL, Tekkis PP, Turley H, Silver A, McDonald PJ, et al. Hypoxia-inducible factor-1alpha and -2alpha are expressed in most rectal cancers but only hypoxia-inducible factor-1alpha is associated with prognosis. Br J Cancer (2009) 100(10):1666-73. doi:10.1038/sj.bjc.6605026

57. Roh JL, Cho KJ, Kwon GY, Choi SH, Nam SY, Kim SY. Prognostic values of pathologic findings and hypoxia markers in 21 patients with salivary duct carcinoma. J Surg Oncol (2008) 97(7):596-600. doi:10.1002/jso.21045

58. Roh JL, Cho KJ, Kwon GY, Ryu CH, Chang HW, Choi SH, et al. The prognostic value of hypoxia markers in T2-staged oral tongue cancer. Oral Oncol (2009) 45(1):63-8. doi:10.1016/j.oraloncology.2008.03.017

59. Yang SL, Liu LP, Niu L, Sun YP, Yang XR, Fan J, et al. Downregulation and pro-apoptotic effect of hypoxia-inducible factor 2 alpha in hepatocellular carcinoma. Oncotarget (2016) 7(23):34571-81. doi:10.18632/oncotarget.8952

60. Sivridis E, Giatromanolaki A, Gatter KC, Harris AL, Koukourakis MI; Tumor and Angiogenesis Research Group. Association of hypoxia-inducible factors 1alpha and 2alpha with activated angiogenic pathways and prognosis in patients with endometrial carcinoma. Cancer (2002) 95(5):1055-63. doi:10.1002/cncr.10774

61. Smeland E, Kilvaer TK, Sorbye S, Valkov A, Andersen S, Bremnes RM, et al. Prognostic impacts of hypoxic markers in soft tissue sarcoma. Sarcoma (2012) 2012:541650. doi:10.1155/2012/541650

62. Sun HX, Xu Y, Yang XR, Wang WM, Bai H, Shi RY, et al. Hypoxia inducible factor 2 alpha inhibits hepatocellular carcinoma growth through the transcription factor dimerization partner 3/E2F transcription factor 1-dependent apoptotic pathway. Hepatology (2013) 57(3):1088-97. doi:10.1002/hep.26188

63. Tong WW, Tong GH, Chen XX, Zheng HC, Wang YZ. HIF2alpha is associated with poor prognosis and affects the expression levels of survivin and cyclin D1 in gastric carcinoma. Int J Oncol (2015) 46(1):233-42. doi:10.3892/ ijo.2014.2719

64. Wang HX, Qin C, Han FY, Wang XH, Li N. HIF-2alpha as a prognostic marker for breast cancer progression and patient survival. Genet Mol Res (2014) 13(2):2817-26. doi:10.4238/2014.January.22.6

65. Wang M, Chen MY, Guo XJ, Jiang JX. Expression and significance of HIF1alpha and HIF-2alpha in pancreatic cancer. J Huazhong Univ Sci Technolog Med Sci (2015) 35(6):874-9. doi:10.1007/s11596-015-1521-3

66. Winter SC, Shah KA, Han C, Campo L, Turley H, Leek R, et al. The relation between hypoxia-inducible factor (HIF)-1alpha and HIF-2alpha expression with anemia and outcome in surgically treated head and neck cancer. Cancer (2006) 107(4):757-66. doi:10.1002/cncr.21983

67. Yang SL, Liu LP, Jiang JX, Xiong ZF, He QJ, Wu C. The correlation of expression levels of HIF-1alpha and HIF-2alpha in hepatocellular carcinoma with capsular invasion, portal vein tumor thrombi and patients' clinical outcome. Jpn J Clin Oncol (2014) 44(2):159-67. doi:10.1093/jjco/hyt194

68. Zhang Q, Lou Y, Zhang J, Fu Q, Wei T, Sun X, et al. Hypoxia-inducible factor-2alpha promotes tumor progression and has crosstalk with Wnt/ beta-catenin signaling in pancreatic cancer. Mol Cancer (2017) 16(1):119. doi:10.1186/s12943-017-0689-5

69. Zhu GQ, Tang YL, Li L, Zheng M, Jiang J, Li XY, et al. Hypoxia inducible factor 1alpha and hypoxia inducible factor 2alpha play distinct and functionally overlapping roles in oral squamous cell carcinoma. Clin Cancer Res (2010) 16(19):4732-41. doi:10.1158/1078-0432.CCR-10-1408

70. Tierney JF, Stewart LA, Ghersi D, Burdett S, Sydes MR. Practical methods for incorporating summary time-to-event data into meta-analysis. Trials (2007) 8:16. doi:10.1186/1745-6215-8-16

71. Razorenova OV, Finger EC, Colavitti R, Chernikova SB, Boiko AD, Chan CK, et al. VHL loss in renal cell carcinoma leads to up-regulation of CUB domain-containing protein 1 to stimulate $\mathrm{PKC}\{$ delta\}-driven migration. Proc Natl Acad Sci U S A (2011) 108(5):1931-6. doi:10.1073/pnas.1011777108

72. van Kuijk SJ, Yaromina A, Houben R, Niemans R, Lambin P, Dubois LJ. Prognostic significance of carbonic anhydrase IX expression in cancer patients: a meta-analysis. Front Oncol (2016) 6:69. doi:10.3389/fonc.2016.00069

73. Viechtbauer $\mathrm{W}$. Conducting meta-analyses in $\mathrm{R}$ with the meta for package. J Stat Softw (2010) 36(3):1-48. doi:10.18637/jss.v036.i03

74. DerSimonian R, Laird N. Meta-analysis in clinical trials. Control Clin Trials (1986) 7(3):177-88.

75. Fan Y, Li H, Ma X, Gao Y, Chen L, Li X, et al. Prognostic significance of hypoxia-induciblefactor expression in renal cell carcinoma: a PRISMA-compliant systematic review and meta-analysis. Medicine (2015) 94(38):e1646. doi:10.1097/ MD. 0000000000001646

76. Leek RD, Lewis CE, Whitehouse R, Greenall M, Clarke J, Harris AL Association of macrophage infiltration with angiogenesis and prognosis in invasive breast carcinoma. Cancer Res (1996) 56(20):4625-9.

77. Leek RD, Talks KL, Pezzella F, Turley H, Campo L, Brown NS, et al. Relation of hypoxia-inducible factor-2 alpha (HIF-2 alpha) expression in tumor-infiltrative macrophages to tumor angiogenesis and the oxidative thymidine phosphorylase pathway in human breast cancer. Cancer Res (2002) 62(5):1326-9.

78. Imtiyaz HZ, Williams EP, Hickey MM, Patel SA, Durham AC, Yuan LJ, et al. Hypoxia-inducible factor 2alpha regulates macrophage function in mouse models of acute and tumor inflammation. J Clin Invest (2010) 120(8): 2699-714. doi:10.1172/JCI39506

79. Ema M, Taya S, Yokotani N, Sogawa K, Matsuda Y, Fujii-Kuriyama Y. A novel bHLH-PAS factor with close sequence similarity to hypoxia-inducible factor 1alpha regulates the VEGF expression and is potentially involved in lung and vascular development. Proc Natl Acad Sci U S A (1997) 94(9):4273-8. doi:10.1073/pnas.94.9.4273

80. Tian H, McKnight SL, Russell DW. Endothelial PAS domain protein 1 (EPAS1), a transcription factor selectively expressed in endothelial cells. Genes $\operatorname{Dev}$ (1997) 11(1):72-82. doi:10.1101/gad.11.1.72

81. Flamme I, Frohlich T, von Reutern M, Kappel A, Damert A, Risau W. HRF, a putative basic helix-loop-helix-PAS-domain transcription factor is closely related to hypoxia-inducible factor-1 alpha and developmentally 
expressed in blood vessels. Mech Dev (1997) 63(1):51-60. doi:10.1016/ S0925-4773(97)00674-6

82. Ladoux A, Frelin C. Cardiac expressions of HIF-1 alpha and HLF/EPAS, two basic loop helix/PAS domain transcription factors involved in adaptative responses to hypoxic stresses. Biochem Biophys Res Commun (1997) 240(3):552-6. doi:10.1006/bbrc. 1997.7708

83. Wiesener MS, Turley H, Allen WE, Willam C, Eckardt KU, Talks KL, et al. Induction of endothelial PAS domain protein-1 by hypoxia: characterization and comparison with hypoxia-inducible factor-1alpha. Blood (1998) 92(7):2260-8.

84. Jain S, Maltepe E, Lu MM, Simon C, Bradfield CA. Expression of ARNT, ARNT2, HIF1 alpha, HIF2 alpha and Ah receptor mRNAs in the developing mouse. Mech Dev (1998) 73(1):117-23. doi:10.1016/S0925-4773(98) 00038-0

85. Bersten DC, Sullivan AE, Peet DJ, Whitelaw ML. bHLH-PAS proteins in cancer. Nat Rev Cancer (2013) 13(12):827-41. doi:10.1038/nrc3621

86. Wiesener MS, Jurgensen JS, Rosenberger C, Scholze CK, Horstrup JH, Warnecke C, et al. Widespread hypoxia-inducible expression of HIF-2alpha in distinct cell populations of different organs. FASEB J (2003) 17(2):271-3. doi:10.1096/fj.02-0445fje
87. Keith B, Johnson RS, Simon MC. HIF1alpha and HIF2alpha: sibling rivalry in hypoxic tumour growth and progression. Nat Rev Cancer (2011) 12(1):9-22. doi: $10.1038 / \mathrm{nrc} 3183$

88. Liao D, Corle C, Seagroves TN, Johnson RS. Hypoxia-inducible factor-1alpha is a key regulator of metastasis in a transgenic model of cancer initiation and progression. Cancer Res (2007) 67(2):563-72. doi:10.1158/0008-5472.CAN-06-2701

89. Chen W, Hill H, Christie A, Kim MS, Holloman E, Pavia-Jimenez A, et al. Targeting renal cell carcinoma with a HIF-2 antagonist. Nature (2016) 539:112-7. doi:10.1038/nature19796

Conflict of Interest Statement: The authors declare that the research was conducted in the absence of any commercial or financial relationships that could be construed as a potential conflict of interest.

Copyright $\odot 2018$ Moreno Roig, Yaromina, Houben, Groot, Dubois and Vooijs. This is an open-access article distributed under the terms of the Creative Commons Attribution License (CC BY). The use, distribution or reproduction in other forums is permitted, provided the original author(s) and the copyright owner are credited and that the original publication in this journal is cited, in accordance with accepted academic practice. No use, distribution or reproduction is permitted which does not comply with these terms. 